\title{
PESQUISA-AÇÃO PARA MELHORAR PROCESSOS DE PROJETO PARTICIPATIVO EM PROPOSTAS DE VINCULAÇÃO DA FACULDADE DE ARQUITETURA COM A COMUNIDADE: UM ESTUDO DE CASO NO EQUADOR
}

\author{
Andrea Jaramillo Benavides, Me. (UFSC/ UTE); \\ Myrian Larco Benítez, Me. (UTE/ UNEX).
}

PALAVRAS CHAVE

Pesquisa-ação; projeto participativo; projetos sociais; Arquitetura.

Key Words

Action research; participatory Architecture; social projects.

\section{RESUMO}

A responsabilidade social é um tema importante para os centros de educação superior. Muitas universidades destinam fundos para a execução de projetos sociais. Esses projetos se desenvolvem num contexto onde é preciso aproveitar ao máximo os recursos disponíveis. É neste cenário que este trabalho apresenta a pesquisa-ação como uma metodologia que permite avaliar e melhorar a execução de projetos sociais desenvolvidos dentro da universidade, na procura de mais eficiência e maiores impactos. Por meio de um estudo de caso desenvolvido numa universidade no Equador, foi possível visibilizar as dificuldades e potencialidades da prática usada na execução dos projetos de vinculação com a sociedade, implementar mudanças na prática e avaliar os resultados.

\section{ABSTRACT}

Social responsibility is an important issue for the universities. They have funds for the implementation of social projects; its background requires making the most with the available resources. In this context, this paper presents the action research as a methodology to evaluate and improve the implementation of university social projects; the goal is more efficiency and higher impacts. Through a case study developed at a university in Equator, it was possible to visualize the weaknesses and strengths of the practice used in the execution of social projects, implement changes and assess the results. 


\section{INTRODUÇÃO}

A universidade tem importância na formação de cidadãos que participem ativamente da coletividade. E como foi declarado pela UNESCO (1998) "a pertinência da Educação Superior deve ser avaliada em função da adequação entre o que a sociedade espera das instituições e o que elas fazem".

É por isso que as universidades além de adaptar suas atividades de pesquisa e formação profissional às demandas da sociedade também possuem programas de responsabilidade social, que em muitos casos incluem projetos de cooperação que são desenvolvidos por estudantes e professores em resposta a determinada problemática social do meio.

A sustentabilidade social desses projetos é fundamental para a inserção e o impacto positivo das atividades acadêmicas na sociedade.

No Equador as instituições de educação superior devem desenvolver programas que, atendendo aos objetivos do Plano Nacional de Desenvolvimento, incluam projetos de "vinculação com a coletividade" para contribuir com a solução de problemáticas locais. Todos os professores e estudantes devem cumprir com uma carga horária mínima de participação nesses empreendimentos.

Nesse contexto na Faculdade de Arquitetura frequentemente são requeridos projetos arquitetônicos de edifícios que satisfaçam determinadas necessidades da população. A principal metodologia utilizada para desenvolvê-los é o projeto participativo, que permite a relação direta dos projetistas com "os clientes".

García (2012) explica o papel do Arquiteto como "arquiteto-intérprete" na sociedade atual: onde o profissional interage com a comunidade, recebe toda a informação e, baseado no próprio conhecimento arquitetônico, racionaliza a problemática dentro do contexto social para finalmente formular uma solução adequada.

Dessa maneira, o uso da metodologia do projeto participativo nas atividades de vinculação faz parte da formação integral dos estudantes, porque aproxima-os ao do contato com os clientes no contexto que desenvolverão suas atividades profissionais no futuro.

No entanto, com o passar do tempo se faz necessário implementar melhorias na metodologia dos projetos de vinculação com a comunidade para ter processos mais eficientes, atingir um maior impacto e também auxiliar a novos professores que queiram propor novos empreendimentos na área.

É assim que por meio de um estudo de caso se desenvolveu um processo de pesquisa-ação, que "se aplica a projetos em que os práticos buscam efetuar transformações em suas próprias práticas" (DOWLING; BROWN, 2010, p.153). É um mecanismo para tomar consciência dos princípios que conduzem determinado trabalho. (MCNIFF, 2010)

Ao desenvolver uma pesquisa qualitativa que acontece paralelamente com a ação estudada é necessário reconhecer que os resultados dependerão de vários fatores: participantes (e grau de intervenção de cada um), reflexão sobre o que se quer mudar do projeto e estratégias adotadas, o jeito de administrar o conhecimento e a ética. (TRIPP, 2005).

O estudo de caso foi desenvolvido num projeto de vinculação com a comunidade, apresentado pela Faculdade de Arquitetura, Artes e Design da Universidad Tecnológica Equinoccial e executado entre 2014 e 2015 na província de Pichincha no Equador.

\section{DESENVOLVIMENTO}

\subsection{Metodologia}

Para o desenvolvimento da pesquisa foi utilizada a pesquisa-ação definida por Tripp (2005) como um processo contínuo, sistemático e empiricamente fundamentado para aprimorar uma prática. Escolheu-se este método porque a pesquisa-ação atua simultaneamente nos campos da prática e da pesquisa científica e a Tabela 1 (seguinte página) mostra como se apresenta a sequência de atividades, as ações desenvolvidas e o estudo da "ação" num ciclo de pesquisa.

A pesquisa-ação altera ao mesmo tempo o que está sendo pesquisado, neste caso o processo de execução do projeto de vinculação com a comunidade. Posto que é uma metodologia participativa, está limitada pelo contexto e pela ética da prática.

Tabela 01: Representação do ciclo de pesquisa

\begin{tabular}{|l|l|l}
\hline \multirow{2}{*}{$\begin{array}{c}\text { Sequéncia da } \\
\text { açào }\end{array}$} & \multicolumn{2}{|c}{ Açăo realizada no campo da } \\
\cline { 2 - 3 } & \multicolumn{1}{|c|}{ Prática } & \multicolumn{1}{c}{ Pesquisa } \\
\hline Planejamento & $\begin{array}{l}\text { De uma } \\
\text { mudança } \\
\text { naprática }\end{array}$ & $\begin{array}{l}\text { Da avaliação de } \\
\text { resultados }\end{array}$ \\
\hline Implementaçăo & $\begin{array}{l}\text { Da } \\
\text { mudança } \\
\text { naprática }\end{array}$ & $\begin{array}{l}\text { Da produçáode } \\
\text { dados }\end{array}$ \\
\hline Avaliaçào & & $\begin{array}{l}\text { a) Da mudança } \\
\text { da prática } \\
\text { b) Doprocesso } \\
\text { de pesquisaraçăo }\end{array}$ \\
\hline
\end{tabular}

Fonte: TRIPP (2005, p. 453) 
Para a realização das atividades de pesquisa-ação foi adaptado o relatório-tipo de Tripp (2005) que tem as seguintes partes: introdução, reconhecimento (da situação, participantes, práticas atuais e intencionalidade), desenvolvimento dos ciclos, conclusões.

A seguir está uma síntese da pesquisa-ação desenvolvida, partindo da observação da situação inicial da metodologia, inclui-se a análise feita durante cada fase da execução até a conclusão do projeto.

2.2. Pesquisa-ação no projeto de vinculação com a comunidade

Antes de começar o trabalho com o projeto foi caraterizado o contexto em que geralmente se desenvolvem esses tipos de atividades de vinculação na universidade, depois se propuseram as ações que seriam executadas para melhorar a metodologia de execução e tentar ter um maior impacto com os mesmos recursos.

Essa análise foi desenvolvida com alguns professores que já concluíram projetos anteriormente a síntese desse processo é apresentada na Tabela 2 (seguinte página).

Nos últimos três anos na Faculdade de Arquitetura se executaram mais de oito projetos diferentes de vinculação com a comunidade. Cada um deles atendeu as necessidades de setores diferentes da população, contou com participantes e colaboradores de distintos perfis profissionais, resolveu problemas específicos, etc.

Apesar dessas variantes se identificou um processo geral que todos eles seguiram, partindo da formulação do projeto até a avaliação, conforme mostra o diagrama 1.

Depois de identificar o contexto e o processo comum entre os projetos de vinculação da Faculdade, foi escolhido um projeto para fazer a pesquisa sobre a implementação das possíveis melhorias.

O nome final do projeto selecionado foi: Apoyo técnico Arquitectónico y Publicitario a la central del Bambú Andoas (CENBA) en el noroccidente de Pichincha.

As mudanças foram aplicadas em todas as fases e a avaliação foi feita ao final de cada uma com a finalidade de corrigir qualquer situação durante a etapa seguinte.

O Diagrama 2 mostra as mudanças implementadas na fase preliminar. Ao final do ciclo se avaliou o impacto dessas ações para poder definir as atividades na fase seguinte.

\section{Fase preliminar}

1. Contato inicial con outras instituiçóes

2. Formulaçáo do projeto

\section{Concurso intemo de projetos na universidade}

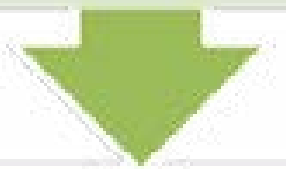

Finedecteruclo do probeto

4. Induçào dos participantes as atividades

5. Elaboração do projeto arquitetónico

6. Revisúes-aceite da proposla

7. Entrega do projeto aos beneficiados

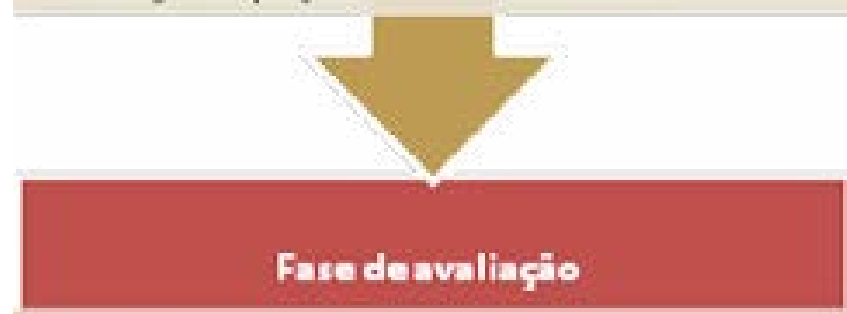

8. Flahoraçăo e enrrega de informes

9. Avaliaçaิo e pre daçào de contas 
Tabela 02: Reconhecimento inicial do contexto de pesquisa

Cenário em que são desenvolvidos os projetos
de vinculação

Os professores que trabalham no projeto tem a responsabilidade de organizar as atividades com os estudantes e monitorar o avanço de atividades e a qualidade dos produtos. Isto representa uma carga adicional de trabalho.

Os projetos se desenvolvem em cooperação com pelo menos uma instituição externa: seja do Estado, privada, ONG ou organização social.

Geralmente os produtos são projetos arquitetônicos, urbanos ou artísticos, em algumas ocasiões esses projetos até foram executados com a participação dos estudantes e da comunidade.

Os projetos contam com um orçamento limitado para sua execução, é preciso procurar contribuições externas.

Em alguns casos existe um alto número de estudantes que se retiram do projeto antes da conclusão das atividades.

Muitas vezes, depois do processo de projeto participativo, o produto apresentado não satisfaz completamente o cliente, o que ocasiona mudanças no projeto arquitetônico, e isto pode desmotivar os estudantes que participam das atividades.

Não existe uma retroalimentação depois que o projeto foi concluído para a área de vinculação com a coletividade da Faculdade nem da Universidade
Ações propostas para melhoria na prática

Incluir participantes de outras faculdades na equipe do projeto para ter mais interdisciplinaridade e um maior número de participantes envolvidos, aproveitando melhor os recursos.

Fazer um processo de seleção de estudantes interessados em participar do projeto.

Motivar os estudantes com dois mecanismos: a aprendizagem de temas de interesse complementares à sua formação e procurando seu compromisso com a realidade social em que se esteja trabalhando Capacitações.

As atividades que os docentes desenvolvem no projeto podem estar vinculadas às matérias disponíveis na Faculdade.

Procurar o trabalho em rede com instituições que já estejam trabalhando numa área específica, para ter um maior impacto social.

\section{Oferecer produtos complementares entre si.}

Determinar responsabilidades e contribuições específicas para cada uma das instituições cooperantes do projeto.

Dividir a entrega de produtos por fases, no fechamento de cada fase se reestrutura a equipe de trabalho. Permitindo a saída ou ingresso de novos estudantes no projeto sem afetar as atividades.

Fazer uma pré-entrega aos beneficiários com várias opções de anteprojetos, na qual eles possam decidir a opção mais conveniente e fazer observações.

Levar um registro de todas as decisões feitas no processo em relação às modificações do projeto.

Fazer uma reunião com a área de vinculação da Faculdade para dar um feedback do processo, que permita fazer previsões de possíveis problemas em futuros projetos. 
Fase preliminar- mudanças implenentadas

\section{CONTATO COM OUTRAS INSIITUKC̈OES}

- trabalho em redes

Por meio da Re de Inte rnacional do Bambu e Ratam (INBAR) re fez contato com a Mesa Setorial do Bambu do pais, para conhecer as atividades que estavam desenvolvendoe as necessidades especificas de seus participantes interessados numa cooperaça com a universidade akem de expor as possibilidades de trabalho conjunta

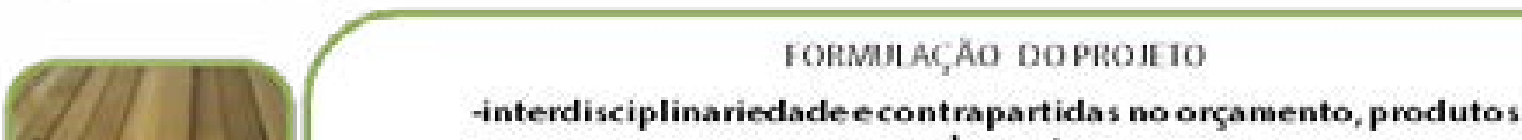 complementares}

Duas instituiçces da Mesa Setorial do Bambu participaram do projeto com a universidade ( $a$ da uma delas também com uma contrapartidas no orçamento), alem disso, as demais se ofereceram para colabocar caso fose necessirio

Foi detectado que alem da faculdack de Arquitetura (escolss de Arquite-tura e Arquitetura Interion) era preciso trabalhar com a Faculdade de Ciências Sociais (publicidade edesign grafico).

Procuraram-se como participantes os docentes com o perfil compativel com as atividades, os estudantes foram selecionados por meio de cartas de intencáa

\section{CONCURSO INTERNO DE PROJETOS NA UNIVERSIDADE}

Aqui nao tiveram variaçoes o projeto completo foi apresentado dentro dos prazos e seguiu oprocesso de seleça

Depois de executar e avaliar o primeiro ciclo foram obtidas algumas conclusões e sinais de melhoria no processo:

- O contato com a Mesa Setorial do Bambu permitiu conhecer a situação atual na área que o projeto iria trabalhar, posto que aí estão mais de 30 instituições do pais envolvidas com o tema. Facilitou a identificação das necessidades do setor. Permitiu mostrarIhes as diferentes disciplinas nas quais se trabalha com os estudantes e as alternativas de cooperação.

- Ao ter na equipe docentes interessados na área específica do projeto, eles se interessaram em pertencer à Mesa Setorial, o que abriu para a universidade um campo de trabalho no futuro.

- Os diretores do projeto foram os docentes universitários, mas o projeto foi formulado conjuntamente com os cooperantes, neste caso a empresa estadual CENBA e a organização internacional INBAR. Isto permitiu definir contrapartidas institucionais no orçamento.
- A empresa estadual CENBA, que produz laminados de bambu, foi a beneficiária direta do projeto. Suas necessidades incluíam: um projeto arquitetônico de adequação do espaço físico atual de operações, o projeto arquitetônico interior de um showroom e, como complemento, uma campanha publicitária que mostre os produtos elaborados com bambu que são oferecidos pela instituição e os fornecedores e artesãos da região.

- A seleção de estudantes por meio de análise de cartas de intenção permitiu incluir no processo pessoas interessadas na temática do projeto, que tinham pré-disposição para colaborar efetivamente no trabalho.

Observando esses resultados iniciou-se o segundo ciclo. O Diagrama 3 mostra as mudanças implementadas na fase de execução do projeto. 
Fase deexecução do projeto - mudanças implementadas
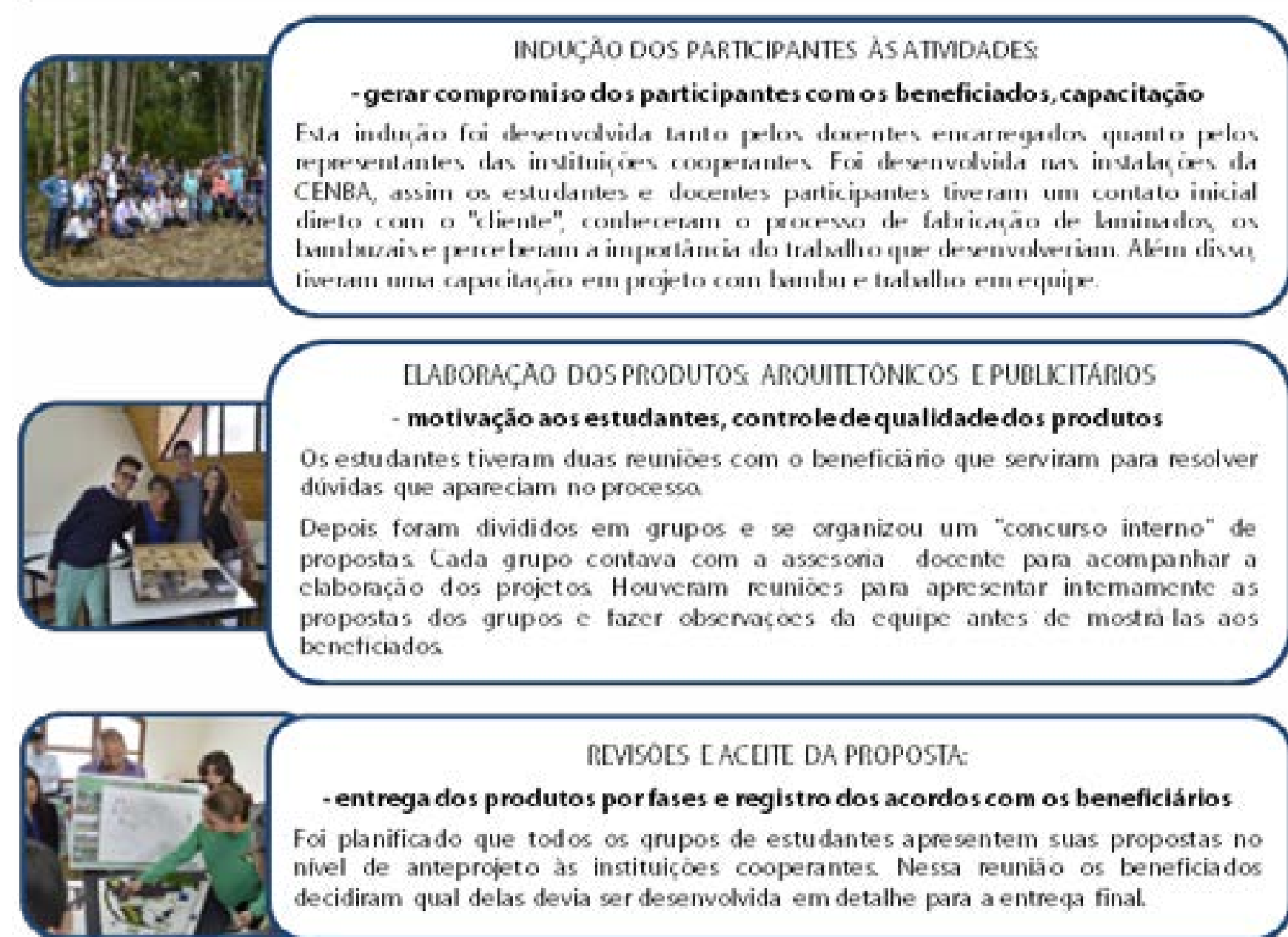

\section{REVSOLS [ACEITL DA PROPOSTA:}

\section{-entrega dos produtos por fases e registro dos acordos com os beneficiários}

Foi planifica do que todos os qrupos de estudantes apresentem suas propostas no nivel de anteprojeto às instituiços cooperantes. Nessa reuniào os beneficiados decidiram qual delas devia ser desenvolvida em detalhe para a entreqa final.

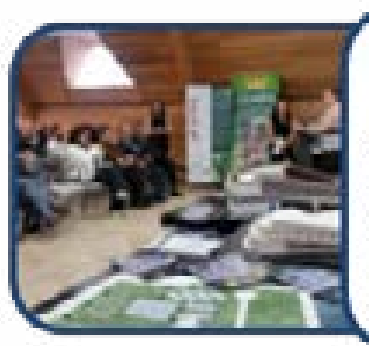

\section{FNTRFGA DO PROIFTO AOS BFNFFKIADOS \\ -otimizaçào de recursos}

Grande parte dos recursos do projeto é destinada ao evento de difusào e entreqa do projeto aos beneficiados. Nesta ocasià o se decidiu fazer este evento compartilhado, quer dizer que dois projetos de vinculaçäo da Faculdade foram entre ques na mesma cerimonia. Para organizar o event o foram incluidos no projeto estudantes da escola de Relaçöes Püblicas

- Na avaliação do segundo ciclo se obtiveram as seguintes observações:

- A indução dos estudantes ao projeto teve várias fases: primeiro uma reunião interna somente com os docentes para conversar sobre a importância dos projetos de vinculação e do compromisso dos participantes, depois a visita ao local do projeto (instalações da CENBA) que foi conduzida pelos beneficiários, onde eles mostraram a situação atual da população dedicada ao bambu na região, contextualizando as atividades que seriam desenvolvidas no projeto e a fase final da indução, foi uma roda de perguntas na qual os estudantes resolviam qualquer dúvida.

- Adicionalmente a instituição cooperante INBAR ofereceu uma capacitação sem custo aos estudantes participantes do projeto, na qual 
- os interessados aprenderam a trabalhar com os laminados de bambu para armar painéis decorativos. Nesta atividade participaram apenas $10 \%$ dos estudantes do projeto.

- Para o processo de elaboração dos anteprojetos arquitetônico, de interiores e publicitário a metodologia escolhida foi dividir os estudantes em grupos para ter mais opções de proposta para os beneficiários e garantir que todos os participantes dos grupos tenham a mesma carga de trabalho. Essa estratégia funcionou com os estudantes da Faculdade de Arquitetura, enquanto na área de publicidade somente serviu para um dos produtos: o logotipo e proposta de imagem corporativa.

- Com os estudantes que trabalhavam nos produtos publicitários o docente que guiava o processo desenvolveu as atividades com uma metodologia diferente: todos tinham reuniões gerais, mas um grupo trabalhava na elaboração do vídeo enquanto os outros faziam o material publicitário impresso e os catálogos dos produtos.

- Durante o processo interno de projeto, se indicou aos estudantes que seriam eles que iriam apresentar e "defender" suas propostas aos beneficiários, que os docentes somente estavam presentes para acompanhar o processo e resolver dúvidas de cada grupo.

- Na primeira fase de entrega, cada grupo de estudantes apresentou os anteprojetos arquitetônicos e de interiores aos representantes da CENBA e INBAR. Neste espaço se conversou principalmente da viabilidade de cada proposta. A decisão adotada pelos beneficiários foi uma combinação das propostas no caso do projeto interior e elegeram somente uma opção entre as propostas arquitetônicas.

- Ao concluir a primeira fase, 5\% dos estudantes participantes se retiraram do projeto, o motivo foi que já tinham o total de horas de vinculação que precisavam.

- Para a segunda fase de elaboração dos projetos (arquitetônico e de interiores), todos os estudantes de cada área trabalharam na elaboração do mesmo produto, as atividades foram divididas entre todos: planos elétricos, sanitários, maquetes, etc.

- Para a entregafinal das propostas aos beneficiados foi organizado um evento conjuntamente com os diretores de outro projeto de vinculação da Faculdade, isso permitiu poupar recursos econômicos e físicos e atrair mais pessoas ao evento. O espaço físico escolhido não foi a melhor opção para mostrar os projetos arquitetônicos.

- O evento de entrega do projeto foi organizado por estudantes da escola de Relações Públicas, que estiveram encarregadas de contatar meios de comunicação para dar cobertura e também organizar a logística.

- Todas as comunicações entre docentes e estudantes foram desenvolvidas por meio de uma rede social, o que permitiu a visualização e resposta imediata de cada tópico.

- O ciclo final do processo corresponde à fase de avaliação, na qual cada um dos participantes do projeto de vinculação entrega um informe de atividades aos diretores, que por sua vez elaboram o informe geral para apresentar no departamento de Vinculação com a Sociedade da Universidade. O diagrama 4 mostra as mudanças implementadas nessa etapa: 
Fase de conclusäo eavaliaçäo do projeto- mudanças impkementadas

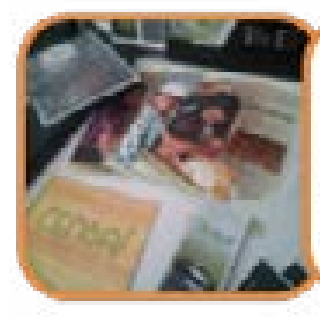

\section{ELABORAÇĀO EENTREGA DE INFORNES}

Cada cstudante apresentou scu intorme $\mathrm{cm}$ formato digital, toda a informaçao do projeto foi coktada pelo diretor do projeta Foi permitido que os estudantes entregassem um CD por grupo, sempre que contenha infomaçäo individual de cada participonte. A direçao do proje to elaborau o informe final

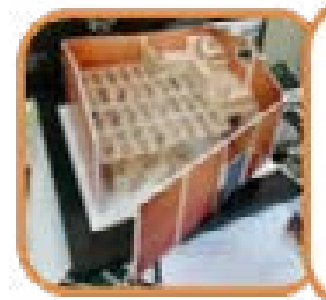

\section{AVALIACAO L PRESTAÇAO DE CONTAS}

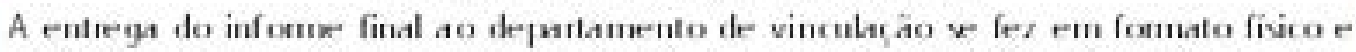
digital.

Houveram tentativas de fazer uma avaliaçà o interna com os participantese um feedbcck com os encarqados de vinculaçäo da Faculdade, mas nào foi possivel porque a diretora do projeto nào póde estar presente.

Depois de avaliar a última fase do projeto, as observações foram:

- $\quad$ A entrega individual de informes, dependendo do número de participantes, dificulta a sistematização dos dados para a elaboração do informe final.

\section{RESULTADOS E DISCUSSÃO}

Os principais resultados positivos das mudanças da prática nos projetos de vinculação foram a pouca desistência dos estudantes durante a execução de atividades; a participação de alunos de cinco diferentes escolas da Universidade: Arquitetura, Arquitetura Interior, Publicidade, Design Gráfico e Relações Públicas; a inclusão da universidade na Mesa Setorial do Bambu e a poupança de recursos durante o processo.

O projeto desenvolvido pela universidade foi incluído no plano operativo anual da Mesa Setorial do Bambu, dentro da qual se formou uma rede de universidades que trabalham no tema. Meses depois foi organizado um seminário internacional no qual vários participantes do projeto (docentes e estudantes) assistiram.

A inclusão de outras escolas da universidade na execução do projeto trouxe novas problemáticas: a metodologia de projeto não pode ser reproduzida em outras áreas, a prática docente dificulta o encontro de espaços de reunião e planificação de atividades com professores de outras escolas, é difícil reunir todos os estudantes no mesmo lugar para ter a oportunidade de intercambiar avanços entre as diferentes disciplinas, o monitoramento dos diferentes produtos deve ser desenvolvido por docentes de cada área que estejam comprometidos com o projeto.

Os problemas oriundos da interdisciplinaridade não representam um impedimento para que se continue trabaIhando por essa linha, ao contrário, exigem prestar maior atenção à conformação da equipe de trabalho e dar maior ênfase ao aproveitamento do tempo de reuniões de planificação.

Houveram estudantes que se retiraram do projeto porque já tinham completado a quantidade de horas de vinculação que precisavam, mas também se teve uma percentagem de estudantes na mesma situação que decidiram permanecer até o final das atividades, sentiam-se comprometidos com o projeto. Nessa circunstância os professores tinham duas opções: pedir-lhes que se retirassem para permitir o ingresso de novos alunos que precisavam cumprir com essa atividade ou deixar concluir o processo.

A decisão de pedir para os estudantes abandonarem o projeto para permitir o ingresso de novos participantes teria aumentado o número de participantes no projeto e melhorado os indicadores no momento do informe final. No entanto optou-se por manter a equipe que iniciou o projeto, porque o compromisso com as atividades faz parte da responsabilidade social que cada indivíduo possui e que a universidade deve incentivar nos estudantes.

Não existe uma ferramenta que permita facilitar a recepção dos informes dos participantes do projeto, a apresentação individual dificulta o processamento de dados para a elaboração do relatório final. Os projetos de vinculação poderiam ser incluídos na plataforma virtual da universidade, permitiria a entrega de arquivos virtuais facilitando 
o monitoramento por parte dos docentes; além disso, facilitaria a geração de indicadores dos projetos.

\section{CONCLUSÕES}

A pesquisa-ação permitiu visualizar os pontos estratégicos a melhorar e as potencialidades da prática usada na execução dos projetos de vinculação com a sociedade da Faculdade de Arquitetura, planificar e executar mudanças em resposta a problemas comuns identificados por executores de projetos anteriores.

Foi possível implementar ações para obter melhorias na execução das atividades planejadas. Essas melhorias foram observadas na equipe de trabalho, na qualidade dos produtos apresentados e nas repercussões posteriores do projeto.

Finalmente por meio da pesquisa-ação foram detectadas outras problemáticas que não puderam ser resolvidas na execução do projeto estudado, mas que podem ser levadas em consideração para futuros trabalhos.

\section{AGRADECIMENTOS}

Ao Departamento de Vinculação com a Coletividade e à Faculdade de Arquitetura, Artes e Design da Universidad Tecnológica Equinoccial.

Aos participantes do projeto de vinculação Apoyo técnico Arquitectónico y Publicitario a la central del Bambú Andoas (CENBA) en el noroccidente de Pichincha.

\section{REFERÊNCIAS}

1. BALDISSERA, Adelina. Pesquisa-ação: uma metodologia do conhecer e do agir coletivo. Sociedade em debate, Pelotas, v.7, n.2, p.5-25, ag.2001. Disponível em: $<$ http://revistas.ucpel.tche.br/index.php/rsd/article/viewFile/570/510>. Acesso em: 18 dez. 2015.

2. CONGRESO UNIVERSIDAD Y COOPERACIÓN AL DESARROLLO, 6., 2013, Valencia. Actas del VI Congreso Universidad y Cooperación al Desarrollo. Valencia: Universitat Politècnica de València, 2013. 1075 p. Disponível em: <http://www.sextocongresocud.es/wp-content/uploads/2013/03/vicongresocud2013_submission_153.pdf >. Acesso em: 30 nov. 2015.

3. DOWLING, Paul; BROWN, Andrew. Doing Research/ Reading Research: Re-interrogating education. 2. ed. New York: Routledge, 2010.
4. GARCÍA, William. Arquitectura Participativa: las formas de lo esencial. Revista de Arquitectura, Bogotá, v. 14, n. 1, p.4-14, jan. 2012. Anual. Disponível em: <http://www. redalyc.org/articuloBasic.oa?id=125125877002>. Acesso em: 18 dez. 2015.

5. MCNIFF, Jean. Action research for professional development: concise advice for new (and experienced) action researchers. York: September Books, 2010. 192 p. Disponível em: <http://www.jeanmcniff.com/>. Acesso em: 12 dez. 2015.

6. TRIPP, David. Pesquisa-ação: Uma introdução metodológica. Educação e Pesquisa, São Paulo, v. 31, n. 3, p.443-446, set. 2005. Disponível em: <http://www.scielo. br/pdf/ep/v31n3/a09v31n3>. Acesso em: 10 dez. 2015.

8. UNITED NATIONS EDUCATIONAL SCIENTIFIC AND CULTURAL ORGANIZATION (UNESCO). La Educación Superior en el siglo XXI: visión y acción. París: Unesco, 1998. Tomo I. Disponível em: <http://unesdoc.unesco. org/images/0011/001163/116345s.pdf>. Acesso em: 17 dez. 2015. 